\title{
How much does early fundoplication for lung transplant recipients with gastroesophageal reflux disease truly help? Challenges in escaping the perils of retrospective review
}

\author{
Mara B. Antonoff, MD
}

From the University of Texas MD Anderson Cancer Center, Houston, Tex.

Disclosures: Author has nothing to disclose with regard to commercial support.

Received for publication Feb 20, 2018; accepted for publication Feb 23, 2018; available ahead of print March 17. 2018

Address for reprints: Mara B. Antonoff, MD, 1400 Pressler St, Unit 1489, Houston, TX 77030 (E-mail: mbantonoff@mdanderson.org).

J Thorac Cardiovasc Surg 2018;155:2772-3

0022-5223/ $\$ 36.00$

Copyright (c) 2018 by The American Association for Thoracic Surgery

https://doi.org/10.1016/j.jtcvs.2018.02.057

The relationship between gastroesophageal reflux disease (GERD) and post-transplantation bronchiolitis obliterans syndrome (BOS) represents a topic of keen interest to thoracic surgeons, highlighting the interplay between 2 areas of our surgical repertoire: benign esophageal disease and end-stage lung failure. Although a number of contributing factors have been identified in the development and progression of BOS, ${ }^{1,2}$ GERD may importantly be one cause that is modifiable.

In this issue of the Journal, Dr Roy and colleagues ${ }^{3}$ describe their comparison of early versus late fundoplication to treat GERD after lung transplantation and the ultimate impact on the rate of decline in lung function. ${ }^{3}$ This well-written article covers a particularly noteworthy topic of great relevance to our specialty. Although previous investigations have explored the impact of antireflux procedures on aspiration and pulmonary function in lung transplant recipients, this is the first study to delve into the optimal timing of antireflux procedures in this patient population. ${ }^{3-6}$

The authors found that fundoplication within 6 months of transplantation appeared to have a protective effect against GERD-induced lung damage, with less decline in spirometry values over time compared with those who underwent delayed antireflux procedures. Overall, the findings are compelling, and these results would suggest that patients with lung transplant should undergo aggressive, early evaluation and intervention for GERD.

However, because this is a retrospective study, one must always consider the presence of unaccounted variables confounding the pulmonary function of study participants differently between the 2 groups. Ultimately, for patients with substantial perioperative complications or worse overall health at the time of transplantation, the likelihood of early referral for fundoplication would be expected to be less than that of an individual who sails through

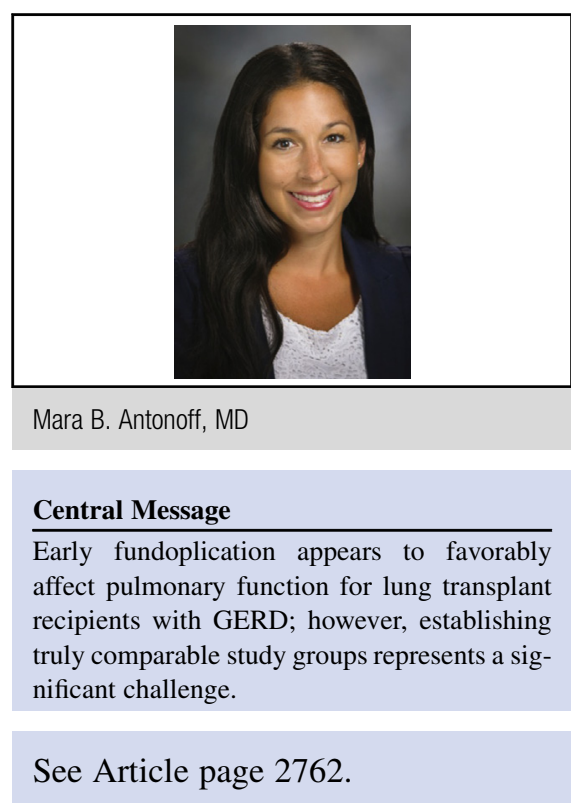

transplantation without a hitch. Likewise, one would expect that recipients with more complex hospital courses would also be at greater risk of declining pulmonary function. ${ }^{7}$ In this study, the late fundoplication group had more episodes of rejection, which seems strikingly relevant. Perhaps these patients were destined to have worse outcomes from their transplanted lungs, regardless, and fundoplications were delayed because they were struggling with rejection and declining lung function. It is incredibly challenging to separate out these contributing factors, particularly in a cohort of patients for whom there is such a massive dichotomy in outcomes between the cases that go well and those that do not.

Despite the limitations, the authors truly are to be commended. They have explored a very practical question, unveiling results that suggest a particularly easy-toexecute solution: perform antireflux procedures often and early. Although the investigators cannot escape the inherent limitations of the study methodology, this article represents an important first step in elucidating the temporal relationship between antireflux procedures and decline in forced expiratory volume in 1 second for lung transplant recipients. The results of this study serve as valuable impetus to initiate a randomized, controlled trial comparing the strategies of early versus late fundoplication. 


\section{References}

1. Belperio JA, Weigt SS, Fishbein MC, Lynch JP III. Chronic lung allograft rejection: mechanisms and therapy. Proc Am Thorac Soc. 2009;6; 108-21.

2. Weigt SS, Wallace WD, Derhovanessian A, Saggar R, Saggar R, Lynch JP, et al. Chronic allograft rejection: epidemiology, diagnosis, pathogenesis, and treatment. Semin Respir Crit Care Med. 2010;31: 189-207.

3. Roy SB, Elnahas S, Serrone R, Haworth C, Olson MT, Kang P, et al. Early fundoplication is associated with slower decline in lung function after lung transplantation in patients with gastroesophageal reflux disease. J Thorac Cardiovasc Surg. 2018;155:2762-71.e1.

4. Fisichella PM, Davis CS, Gagermeier J, Dilling D, Alex CG, Dorfmeister JA, et al. Laparoscopic antireflux surgery for gastroesophageal reflux disease after lung transplantation. J Surg Res. 2011;170:e279-86.

5. Fisichella PM, Davis CS, Lowery E, Pittman M, Gagermeier J, Love RB, et al. Pulmonary immune changes early after laparoscopic antireflux surgery in lung transplant patients with gastroesophageal reflux disease. J Surg Res. 2012;177:e65-73.

6. Fisichella PM, Davis CS, Lundberg PW, Lowery E, Burnham EL, Alex CG, et al. The protective role of laparoscopic antireflux surgery against aspiration of pepsin after lung transplantation. Surgery. 2011;150:598-606.

7. Chan EG, Bianco V III, Richards T, Hayanga JW, Morrell M, Shigemura N, et al The ripple effect of a complication in lung transplantation: evidence for increased long-term survival risk. J Thorac Cardiovasc Surg. 2016;151:1171-9. 